\title{
The usefulness of the basophil activation test in monitoring specific immunotherapy with house dust mite allergens
}

\author{
Ewa M. Czarnobilska ${ }^{1}$, Małgorzata Bulanda ${ }^{1}$, Radosław Śpiewak ${ }^{2}$
}

'Department of Clinical and Environmental Allergology, Faculty of Medicine, Jagiellonian University, Krakow, Poland 2Department of Experimental Dermatology and Cosmetology, Faculty of Pharmacy, Jagiellonian University, Krakow, Poland

Adv Dermatol Allergol 2018; XXXV (1): 93-98 DOI: https://doi.org/10.5114/ada.2018.73169

\begin{abstract}
Introduction: In clinical practice, reliable tools for monitoring specific immunotherapy (SIT) are of utmost importance.

Aim: To assess the usefulness of the basophil activation test (BAT) in monitoring SIT in paediatric patients with allergy to house dust mites (HDM).

Material and methods: Thirty-one children qualified for SIT with HDM, of whom 21 completed the SIT during the observation period. The BAT was carried out prior to commencing the SIT (time point BAT1) and upon finishing the initial pack of allergy vaccine (cumulative dose of allergen 12487.5 PNU; BAT2), as well as after the second vaccine pack (cumulative dose of allergen 23750.0 PNU; BAT3). Peripheral blood of the patients was stimulated with allergen solutions in five concentrations from $0.00225 \mathrm{ng} / \mathrm{ml}$ to $22.5 \mathrm{ng} / \mathrm{ml}$. Basophil activation was measured by CD63 expression in flow cytometry.

Results: For the allergen concentration of $0.225 \mathrm{ng} / \mathrm{ml}$, a statistically significant decrease in median basophil activation was observed, from $51.29 \%$ at BAT1 to $8.48 \%$ at BAT2 $(p=0.004)$ and $4.21 \%$ at BAT3 $(p<0.001)$. For the allergen concentration of $0.0225 \mathrm{ng} / \mathrm{ml}$, a statistically significant decrease was seen between BAT1 (1.72\%) and BAT3 $(0.21 \%, p=0.01)$. Median CD-sens index decreased significantly from 1099.02 at BAT1 to 179.31 at BAT2 $(p<0.002)$ and 168.04 at BAT3 $(p<0.001)$.

Conclusions: There is a significant decrease in BAT results in the course of specific immunotherapy with HDM allergens in children, with the optimum allergen concentration for monitoring basophil response at $0.225 \mathrm{ng} / \mathrm{ml}$. The CD-sens index seems to be a better monitoring parameter than the plain percentage of CD63-expressing basophils.
\end{abstract}

Key words: basophil activation test, CD-sens, monitoring of specific immunotherapy.

\section{Introduction}

Allergic symptoms may be alleviated with medications; however, only specific immunotherapy (SIT) constitutes a causal treatment of atopic diseases. The SIT may interrupt the "allergic march" and cause clinical improvement to persist years after cessation of the treatment [1]. Unfortunately, providing a univocal answer to the question of the optimum duration of immunotherapy in a given patient proves difficult in clinical conditions. The clinical effectiveness of SIT seems to be related to the administered dose of allergen, rather than merely the duration of the therapy; therefore, assessing the therapeutic effects after administering defined cumula- tive doses of allergen seems reasonable [2]. In practice, the time of administration of the same cumulative dose may vary substantially, which is due to individual tolerance and compliance, as well as complicating health conditions (e.g. infections). The role of basophils in the allergic reaction and in development of immunological tolerance during SIT has been studied intensively [3]. It is assumed that basophil stimulation in vitro replicates an in vivo mechanism that leads to the development of allergic symptoms. The SIT has been demonstrated to modulate basophil and mastocyte activation thresholds and decreases IgE-mediated histamine release [4, 5]. Studies into the course of immunotherapy demonstrated that SIT initially decreases basophil activation by the al-

Address for correspondence: Radosław Śpiewak MD, PhD, Department of Experimental Dermatology and Cosmetology, Faculty of Pharmacy, Jagiellonian University, 9 Medyczna St, 30-688 Krakow, Poland, +48 12620 58 30, e-mail: radoslaw.spiewak@uj.edu.pl Received: 15.09.2016, accepted: 1.12.2016. 
lergen with a subsequent decrease in basophil count and production of interleukin (IL)-4 and IL-13 [6]. The decrease in basophil activation as well as depletion of mediator reserves due to repetitive allergen stimulation is considered as the key mechanism at early stages of SIT [7]. Hence, a decrease in basophil activation in response to the allergen in vitro seems a promising marker of clinical tolerance developing during the course of SIT [8].

Despite basophil activation test (BAT) being considered as an aid in diagnosis of airborne allergy, drug allergy, Hymenoptera venom allergy, and in autoimmune urticaria, as well as in qualification for SIT, the protocols used and results obtained still vary from centre to centre [9]. Basophil activation markers with proven sensitivity and specificity are CD63 and CD203c. CD63, i.e. lysosomalassociated membrane glycoprotein-3, LAMP-3 in a resting basophil is located in the membrane of intracellular secretory granules. Upon FceRI activation, it is expressed on the basophil surface [10]. CD203c to is a transmembranous, glycosylated molecule, which is constitutively present on basophil surfaces, and upon being activated by allergen its expression increases [11]. Both markers are characterised by similar sensitivity and specificity. CD63 is used more widely due to the direct connection between its membrane expression and basophil degranulation $[12,13]$.

Two outcome measures of basophil activations are used: basophil reactivity, i.e. the number of basophils activated by allergen, and basophil sensitivity, i.e. allergen concentration causing half of the basophils to degranulate. Basophil sensitivity provides additional information about the sensitivity to allergen - how much allergen basophils can tolerate before they react. On the curve of reactivity vs. allergen concentration, the eliciting con-

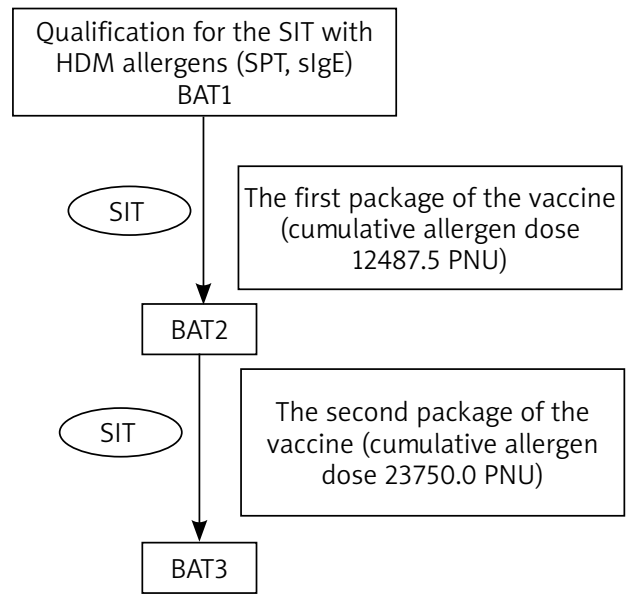

Figure 1. Design of the study. The BAT, SPT, and slgE were carried out prior to commencing the SIT (BAT1) and after completing the initial pack (BAT2; cumulative allergen dose 12487.5 PNU), and after completing two packages (BAT3; cumulative allergen dose $23750 \mathrm{PNU}$ ) centration at which $50 \%$ of basophils respond (EC50) is determined. EC50 can be expressed as 'CD-sens' by inversion and multiplication by 100 . Basophil reactivity may be expressed as 'CD-max' (see below) [9].

\section{Aim}

The aim of the present study was to assess the usefulness of a BAT in monitoring SIT in paediatric patients with allergy to house dust mites (HDM).

\section{Material and methods}

\section{Study protocol}

During the first stage of the study conducted in the years 2010-2012, the results of which were published elsewhere [14], out of the group of 52 children with respiratory allergy aged 7-18 years, 31 had been qualified for SIT with HDM allergens based on the clinical symptoms, skin prick tests (SPT) results, and slgE concentration. The first basophil activation test (BAT1) was carried out in those patients before commencing SIT. Control BATs were performed after administering to the subjects defined cumulative doses of the allergen - respectively 12487.5 PNU (the total allergen amount in the initial pack of allergy vaccines; measuring point (BAT2)) and 23750.0 PNU (cumulative dose from the first and second packs of the vaccine (BAT3)). Figure 1 presents the study design.

Changes in two parameters of basophil activation upon stimulation were analysed during the SIT. The first was calculated by subtracting the baseline basophil activation recorded in the negative control from the maximum activation after stimulation with the allergen at defined concentrations. The second parameter - the CDsens used to describe subjects' sensitivity to the allergen - was calculated by reversing the allergen concentration required to cause CD63 expression on 50\% of all basophils in the sample and multiplying the product by 100 [15]. The study project was approved by the Committee of Bioethics of the Jagiellonian University; opinion no.: KBET/119/B/2011 of 1 July 2011. Written informed consent was obtained for each participant from a parent.

\section{Basophil activation test}

Patients' blood (each $400 \mu \mathrm{l}$ ) was collected in test tubes containing ethylenediaminetetraacetic acid (EDTA) before commencing SIT (BAT1), after completing the initial pack of allergy vaccine (BAT2), as well as after completing the second pack (BAT3). The test was performed within $2 \mathrm{~h}$ after the blood collection. The assessment of basophil activation by measuring CD63 antigen expression was carried out by means of the Flow2 CAST test (Bühlmann Laboratories AG, Schönenbuch, Switzerland). Anti-FceRI monoclonal antibodies and fMLP oligopeptides were used as a positive control, while an unstimulated 
sample served as a negative control. Cells were stimulated with an allergen of Dermatophagoides pteronyssinus (Dp) at the following concentrations: $22.5 \mathrm{ng} / \mathrm{ml}$, $2.25 \mathrm{ng} / \mathrm{ml}, 0.225 \mathrm{ng} / \mathrm{ml}, 0.0225 \mathrm{ng} / \mathrm{ml}$, and $0.00225 \mathrm{ng} /$ $\mathrm{ml}$. A mixture of FITC-conjugated anti-CD63 monoclonal antibodies, and PE-conjugated anti-CCR3 antibodies was added to the cellular suspension and incubated for $15 \mathrm{~min}$ at $37^{\circ} \mathrm{C}$, after which $2 \mathrm{ml}$ of erythrocyte lysing solution were added, samples were centrifuged, resuspended in $0.3 \mathrm{ml}$ of washing buffer, and analysed within $1 \mathrm{~h}$ on a flow cytometer (FACSCalibur, Becton, Dickinson and Company, New Jersey, USA) with basophils gated as $\mathrm{CCR}^{+} / \mathrm{SSC}^{\text {low }}$ cells.

\section{Statistical analysis}

As the distribution of raw data was non-Gaussian, medians were used in the description of results and Wilcoxon's test was applied in testing the statistical significance of differences observed. The analysis was performed using the GraphPad Prism 6 package.

\section{Results}

A total of 31 patients were qualified for the SIT; their results are presented in Table 1 . Of these patients, 21 subjects actually underwent the SIT, of whom 14 (67\%) patients reported for the BAT2 testing 4 weeks after administration of the last dose from the initial pack of the vaccine, and 21 (100\%) patients reported for the BAT3 carried out 4 weeks after administration of the last dose from the second pack of the vaccine. An overview of the results is shown in Figure 2. Significant changes were observed for BAT results expressed as the percentage of activated basophils at the allergen concentrations of 0.225 $\mathrm{ng} / \mathrm{ml}$ and $0.0225 \mathrm{ng} / \mathrm{ml}$, as well as for CD-sens (Table 2). A comparison of indices that decreased significantly in the course of SIT is shown in Figure 3.

\section{Discussion}

In our study, the BAT turned out to be a good objective parameter for the monitoring of SIT with an HDM allergen in children. We applied a protocol measuring basophil activation in whole blood, used a CD63 as a basophil activation marker [14, 16-19], and measured SIT effects after having administered an earlier planned identical cumulative dose of the allergen. In SIT monitoring, we used five 10-fold allergen dilutions identified in the preliminary tests [20]. The basophil activation thus calculated decreased significantly in the second measurement for the concentration of $0.225 \mathrm{ng} / \mathrm{ml}$, and in the third for concentrations of $0.225 \mathrm{ng} / \mathrm{ml}$ and $0.0225 \mathrm{ng} / \mathrm{ml}$ respectively.

So far there have been few studies using a BAT to assess SIT effectiveness in allergy to HDM. In the study by Ciepiela et al. basophil activation after stimulation with Dp or Dermatophagoides farinae (Df) or grass pollen allergens in $0.2 \mathrm{IR} / \mathrm{ml}$ concentration, decreased in the majority of children after a year of sublingual immunotherapy (SLIT) [21]. Sánchez and Cardona observed that basophil activation after Dp simulation in $1 \mathrm{ng} / \mathrm{ml}$ concentration is lower than in the control group after a year of the SIT with Dp/Df allergens in children with atopic dermatitis [22].

The BAT is more often applied in monitoring of immunotherapy for seasonal aeroallergens and Hymenoptera venom. Gokmen et al. for the olive pollen allergen concentration of $1 \mathrm{ng} / \mathrm{ml}$ obtained a decrease in basophil activation after 7 preseasonal injections [23]. In the study Kepil Özdemir et al. basophil activation in response to stimulation with grass allergens in $4.5 \times 10^{-4}$ and $4.5 \times$ $10^{-5} \mathrm{\mu g} / \mathrm{ml}$ concentrations decreased after the completed preseasonal immunotherapy and remained at a low level during the next grass pollination season [24]. Zitnik et al. demonstrated a decrease in CD63 expression output values in response to a submaximal concentration of $0.1 \mu \mathrm{g} /$ $\mathrm{ml}$ after 6 months of desensitisation to bee venom [25]. In a study by Ebo et al., after 6 months of venom immunotherapy (VIT), a decrease in basophil activation, also limited to a submaximal concentration of $0.01 \mathrm{mg} / \mathrm{ml}$, was recorded, which, according to the authors, suggests that 6 months of immunotherapy induces a decrease in a basophil response, but not total suppression of these cells [26].

Not all researchers record decreases in basophil activation during immunotherapy. Van Overtvelt et al. did not observe significant changes in basophil activation despite the slgG induction in patients receiving SLIT with grass pollens for 4 months [27]. Erdmann et al. did not observe a correlation between a change in basophil activation during VIT and a response to a control sting provocation test. Unfortunately, basophil activation was performed with two allergen concentrations, $100 \mathrm{ng}$ and $1 \mu \mathrm{g}$, and due to

Table 1. Basophil activation test results in all 31 patients who were qualified for SIT

\begin{tabular}{lccccc}
\hline Basophil activation* & \multicolumn{4}{c}{ Allergen concentration } \\
\cline { 2 - 5 } & $\mathbf{2 2 . 5} \mathbf{n g} / \mathrm{ml}$ & $\mathbf{2 . 2 5} \mathbf{n g} / \mathrm{ml}$ & $\mathbf{0 . 2 2 5} \mathbf{n g} / \mathrm{ml}$ & $\mathbf{0 . 0 2 2 5} \mathbf{n g} / \mathrm{ml}$ & $\mathbf{0 . 0 0 2 2 5} \mathbf{n g} / \mathrm{ml}$ \\
\hline Median & $64.01 \%$ & $67.49 \%$ & $46.42 \%$ & $4.87 \%$ & $-0.19 \%$ \\
\hline Minimum & $5.20 \%$ & $1.80 \%$ & $-2.67 \%$ & $-5.48 \%$ & $-6.77 \%$ \\
\hline
\end{tabular}

${ }^{*}$ Basophil activation expressed as percent of basophils expressing CD63 on their surface in response to allergen, after subtracting the baseline activity (negative control). 

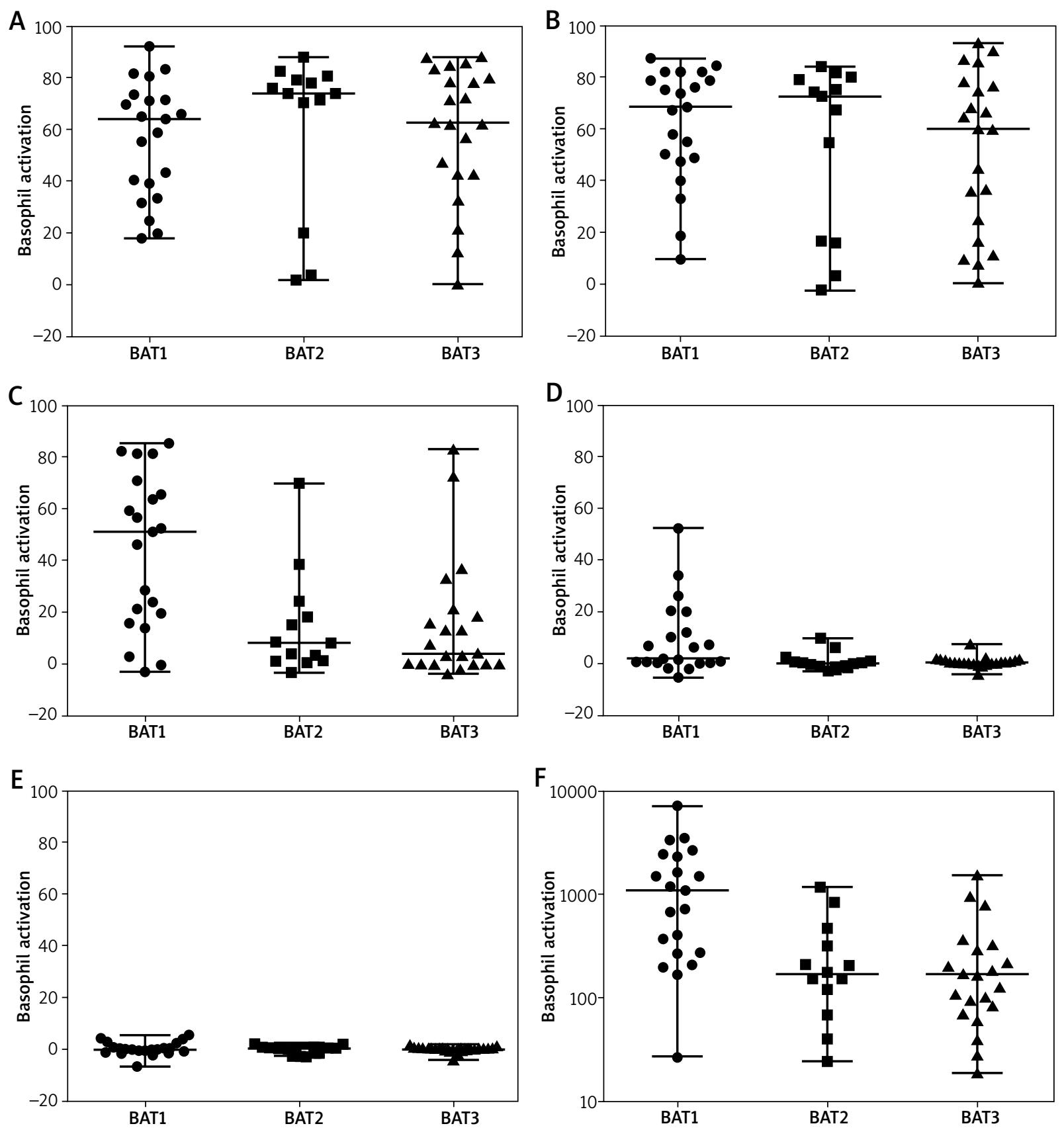

Figure 2. Overview of changes in basophil activation for each concentration $(\mathbf{A}-22.5 \mathrm{ng} / \mathrm{ml}, \mathbf{B}-2.25 \mathrm{ng} / \mathrm{ml}, \mathbf{C}-0.225$ $\mathrm{ng} / \mathrm{ml}, \mathbf{D}-0.0225 \mathrm{ng} / \mathrm{ml}, \mathbf{E}-0.00225 \mathrm{ng} / \mathrm{ml}$ ) and changes in CD-sens $(\mathbf{F})$ during the SIT. Horizontal lines indicate medians and ranges

this fact the authors only assessed the changes in basophil reactivity, but not basophil sensitivity, which may have resulted in obtaining false results $[26,28]$.

The latest publications emphasise that based on CDmax, clinicians may draw erroneous conclusions pertaining to continuation/cessation of a SIT or anti-lgE treatment [29]. In assessing changes in basophil activation during immunotherapy, the CD-sens should be analysed
[30-32]. In our study changes in CD-sens were significant in all the subjects already at the first measurement during the SIT, while in the following determination we observed a further decrease in CD-sens. In the paediatric population, due to the lack of cooperation, it is frequently difficult to perform a specific provocation, constituting a gold standard in assessment of an allergen's impact on the target organ, and, for this reason, application of a CD- 
Table 2. Basophil activation test parameters that changed significantly during specific immunotherapy

\begin{tabular}{|c|c|c|c|c|}
\hline \multirow[t]{2}{*}{ Variable } & & \multicolumn{3}{|c|}{ Measuring point } \\
\hline & & BAT1 & BAT2 & BAT3 \\
\hline \multirow[t]{2}{*}{ Basophil activation at $0.225 \mathrm{ng} / \mathrm{ml}$} & Median & $51.29 \%$ & $8.48 \%^{*}$ & $4.21 \%^{* *}$ \\
\hline & Range & $-2.67-85.48 \%$ & $-2.98-70.13 \%$ & $-3.4-83.27 \%$ \\
\hline \multirow[t]{2}{*}{ Basophil activation at $0.0225 \mathrm{ng} / \mathrm{ml}$} & Median & $1.72 \%$ & $0 \%$ & $0.21 \% *$ \\
\hline & Range & $-5.48-52.32 \%$ & $-2.99-9.55 \%$ & $-4.2-7.29 \%$ \\
\hline \multirow[t]{2}{*}{ CD-sens } & Median & 1099.02 & $179.31^{*}$ & $168.04^{\star \star}$ \\
\hline & Range & $27.26-7256.89$ & $24.52-1181.89$ & $18.90-1544.88$ \\
\hline
\end{tabular}

${ }^{*} p<0.05,{ }^{* *} p<0.001$

sens reflecting the sensitivity to an allergen is of peculiar importance in this group. Our results correlated with a clinical improvement experienced by patients. Similar results were obtained by other authors in the case of SIT monitoring with birch and timothy as well as with Hymenoptera venom. In the study by Nopp et al. a decrease in CD-sens in the early stage of immunotherapy was accompanied by an increase in IgG4 antibody concentration and lack of changes in basophil reactivity [33]. Schmid et al. observed a decrease in basophil sensitivity already after 3 weeks, while Lalek et al. observed a decrease after two months of SIT, which correlated with a reduction in clinical symptoms [34, 35].

\section{Conclusions}

There is a significant decrease in BAT results in the course of specific immunotherapy with HDM allergens in children, with the optimum allergen concentration for monitoring the basophil response at $0.225 \mathrm{ng} / \mathrm{ml}$. The CD-sens index seems a better monitoring parameter than the plain percentage of CD63-expressing basophils.

\section{Acknowledgments}

The study project was financed from the statutory task fund of the Jagiellonian University Medical College K/ZDS/005621.

\section{Conflict of interest}

The authors declare no conflict of interest.

\section{References}

1. Cox L, Calderon M, Pfaar O. Subcutaneous allergen immunotherapy for allergic disease: examining efficacy, safety and cost-effectiveness of current and novel formulations. Immunotherapy 2012; 4: 601-16.

2. Frew AJ, Powell RJ, Corrigan CJ, Durham SR. Efficacy and safety of specific immunotherapy with SQ allergen extract in treatment-resistant seasonal allergic rhinoconjunctivitis. J Allergy Clin Immunol 2006; 117: 319-25.

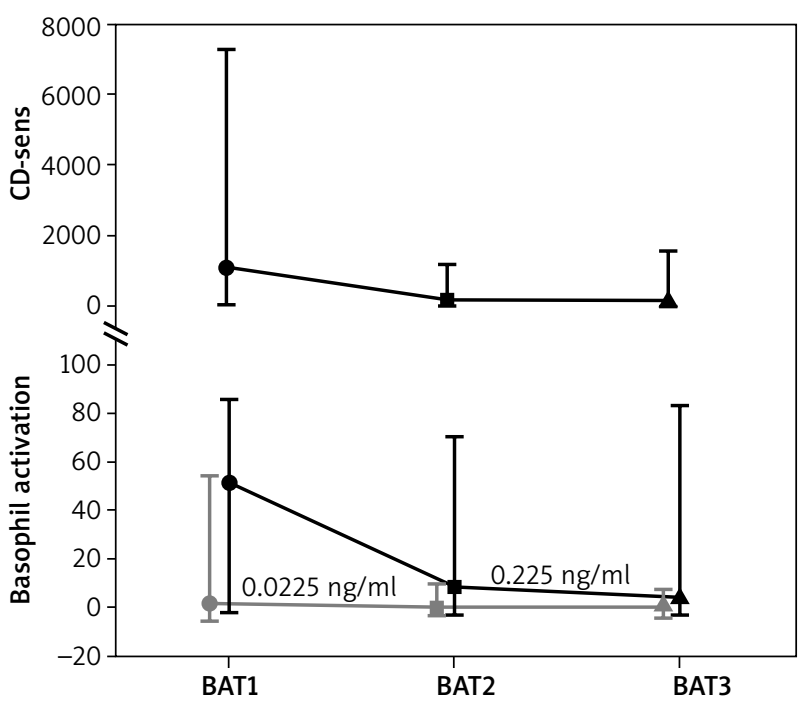

Figure 3. Significant changes in percentages of activated basophils and CD-sens in the course of SIT

3. Patil SU, Shreffler WG. Immunology in the clinic review series; focus on allergies: basophils as biomarkers for assessing immune modulation. Clin Exp Immunol 2012; 167: 59-66.

4. Jutel M, Akdis CA. Immunological mechanisms of allergenspecific immunotherapy. Allergy 2011; 66: 725-32.

5. Maintz L, Bussmann C, Bieber T, Novak N. Contribution of histamine metabolism to tachyphylaxis during the buildup phase of rush immunotherapy. J Allergy Clin Immunol 2009; 123: 701-3.

6. Siegmund R, Vogelsang H, Machnik A, Herrmann D. Surface membrane antigen alteration on blood basophils in patient with Hymenoptera venom allergy under immunotherapy. J Allergy Clin Immunol 2000; 106: 1190-5.

7. Plewako H, Wosińska K, Arvidsson M, et al. Basophil interleukin 4 and interleukin 13 production is suppressed during the early phase of rush immunotherapy. Int Arch Allergy Immunol 2006; 141: 346-53.

8. Mikkelsen S, Bibby BM, Dolberg MK, et al. Basophil sensitivity through CD63 or CD203C is a functional measure for specific immunotherapy. Clin Mol Allergy 2010; 8: 2-10.

9. Hoffmann HJ, Santos AF, Mayorga C, et al. The clinical utility of basophil activation testing in diagnosis and monitoring of allergic disease. Allergy 2015; 70: 1393-405. 
10. Knol EF, Mul FP, Jansen H, et al. Monitoring human basophil activation via CD63 monoclonal antibody 435. J Allergy Clin Immunol 1991; 88: 328-38.

11. Buhring HJ, Simmons PJ, Pudney $M$, et al. The monoclonal antibody 97A6 defines a novel surface antigen expressed on human basophils and their multipotent and unipotent progenitors. Blood 1999; 94: 2343-56.

12. Chirumbolo S. Basophil activation test in allergy: time for an update? Int Arch Allergy Immunol 2012; 158: 99-114.

13. McGowan EC, Saini S. Update on the performance and application of basophil activation tests. Curr Allergy Asthma Rep 2013; 13: 101-9.

14. Czarnobilska E, Gregorius A, Porebski G, et al. [The benefits of using basophil activation test as a diagnostic tool prior to specific immunotherapy with inhalant allergens]. Przegl Lek 2012; 69: 1249-53.

15. Johansson SG, Nopp A, van Hage M, et al. Passive IgE-sensitization by blood transfusion. Allergy 2005; 60: 1192-9.

16. Chirumbolo S. Immunotherapy in allergy and cellular tests: state of art. Hum Vaccin Immunother 2014; 10: 1595-610.

17. Leśniak M, Dyga W, Rusinek B, et al. Comparison of the basophil activation test versus the nasal provocation test in establishing eligibility for specific immunotherapy. Pol Arch Med Wewn 2016; 126: 521-9.

18. Leśniak M, Dyga W, Porębski G, Czarnobilska E. [Basophil activation test - a practical approach to diagnosis of common respiratory allergy]. Przegl Lek 2015; 72: 725-30.

19. De Week AL, Sanz ML, Gamboa PM, et al. Diagnostic tests based on human basophils: more potentials and perspectives than pitfalls. II. Technical issues. J Investig Allergol Clin Immunol 2008; 18: 143-55.

20. Gregorius A. Optymalizacja testu aktywacji bazofilów w diagnostyce i kwalifikacji do leczenia w postaci alergenowej immunoterapii swoistej u dzieci z alergią oddechową na roztocze kurzu domowego. (Thesis). Jagiellonian University Medical College, Krakow 2014.

21. Ciepiela O, Zawadzka-Krajewska A, Kotuła I, Demkow U. The influence of sublingual immunotherapy on several parameters of immunological response in children suffering from atopic asthma and allergic rhinitis depending on asthma features. Pneumonol Alergol Pol 2014; 82: 503-10.

22. Sánchez J, Cardona R. Effect of immunotherapy on basophi activation induced by allergens in patients with atopic dermatitis. Rev Alerg Mex 2014; 61: 168-77.

23. Gokmen NM, Ersoy R, Gulbahar O, et al. Desensitization effect of preseasonal seven-injection allergoid immunotherapy with olive pollen on basophil activation: the efficacy of olive pollen-specific preseasonal allergoid immunotherapy on basophils. Int Arch Allergy Immunol 2012; 159: 75-82.

24. Kepil Özdemir S, Sin BA, Güloğlu D, et al. Short-term preseasonal immunotherapy: is early clinical efficacy related to the basophil response? Int Arch Allergy Immunol 2014; 164: 237-45.

25. Zitnik SE, Vesel T, Avcin T, et al. Monitoring honeybee venom immunotherapy in children with the basophil activation test. Pediatr Allergy Immunol 2012; 23: 166-72.

26. Ebo DG, Hagendorens MM, Schuerwegh AJ, et al. Flow-assisted quantification of in vitro activated basophils in the diagnosis of wasp venom allergy and follow-up of wasp venom immunotherapy. Cytometry B Clin Cytom 2007; 72 196-203.

27. Van Overtvelt L, Baron-Bodo V, Horiot S, et al. Changes in basophil activation during grass-pollen sublingual immuno- therapy do not correlate with clinical efficacy. Allergy 2011; 66: $1530-7$.

28. Erdmann SM, Sachs B, Kwiecien R, et al. The basophil activation test in wasp venom allergy: sensitivity, specificity and monitoring specific immunotherapy. Allergy 2004; 59: 1102-9.

29. Glaumann S, Nopp A, Johansson SG, et al. Basophil allergen threshold sensitivity, CD-sens, IgE-sensitization and DBPCFC in peanut-sensitized children. Allergy 2012; 67: 242-7.

30. MacGlashan DW Jr. Releasability of human basophils: cellular sensitivity and maximal histamine release are independent variables. J Allergy Clin Immunol 1993; 91: 605-15.

31. Nopp A, Johansson SGO, Ankerst J, et al. Basophil allergen threshold sensitivity: a useful approach to anti-IgE treatment efficacy evaluation. Allergy 2006; 61: 298-302.

32. Dahlen B, Nopp A, Johansson SGO, et al. Basophil allergen threshold sensitivity, CD-sens, is a measure of allergen sensitivity in asthma. Clin Exp Allergy 2011; 41: 1091-7.

33. Nopp A, Cardell LO, Johansson SG, Oman H. CD-sens: a biological measure of immunological changes stimulated by ASIT. Allergy 2009; 64: 811-4.

34. Schmid JM, Würtzen PA, Dahl R, Hoffmann HJ. Early improvement in basophil sensitivity predicts symptom relief with grass pollen immunotherapy. J Allergy Clin Immunol 2014; 134: 741-4.

35. Lalek N, Kosnik M, Silar M, Korosec P. Immunoglobulin Gdependent changes in basophil allergen threshold sensitivity during birch pollen immunotherapy. Clin Exp Allergy 2010; 40: 1186-93. 